\title{
Apropiación y uso de las tecnologías de la información y de la comunicación (TIC) en la prensa migrante de las colectividades andinas en la Argentina
}

\section{Appropriation and uses of information and communication technologies (ICT) in the Andean community press in Argentina}

\section{Cecilia E. Melella. Universidad de Buenos Aires (UBA) y CONICET}

Recibido: 18-VI-2013 - Aceptado: 3-X-2013

Resumen:

El uso de las tecnologías de la información y de la comunicación (TIC) como Internet, han transformado formas de organización social en las comunidades de migrantes. Sin embargo, la apropiación y uso de tecnologías por parte de estos colectivos no es un fenómeno nuevo. En la Argentina, la prensa de la inmigración es un antecedente de la apropiación de tecnología por parte de estos grupos. Los usos de saberes que tienen que ver con el universo del periodismo gráfico conviven con aquellos que se circunscriben al universo de la Internet. Este artículo se propone reflexionar sobre la apropiación de las TIC por parte de las comunidades de migrantes andinos en la Argentina y su convivencia con otras prácticas de comunicación precedentes a partir de dos periódicos de inmigrantes que tienen presencia en la Web. Utilizamos una metodología cualitativa basada en el análisis de discurso y de contenido (con herramientas de la semiótica contemporánea) de los sitios Web y dominios de Facebook de Gaceta del Perú (colectividad peruana) y Renacer (colectividad boliviana).

Palabras clave:

Migración andina; TIC; apropiación; periódicos; Argentina.

Abstract:

The information and communication technologies (ICT) such as the Internet, generates new forms of social organization in the migrant communities. However, the appropriation and uses of technologies by migrants it's not new. In Argentina, the immigration press is an antecedent of the appropriation of technology by these groups. The uses of knowledge that has to do with the world of newspaper coexist with those confined to the universe of Internet. The propose of this article is to think about of the appropriation of ICT by Andean migrant communities in Argentina and its coexistence with other previous communication practices from two newspapers of immigrants who have on line presence. We used a qualitative methodology based on the analysis of discourse (with contemporary semiotic perspective) of the websites and Facebook of Gaceta del Perú (Peruvian community) and Renacer (Bolivian community).

Keywords:

Andean migration; ICT; appropriation; newspapers; Argentina. 


\section{Introducción}

Las denominadas tecnologías de la información y de la comunicación (TIC) ${ }^{1}$ tradicionales como el telégrafo o el teléfono han facilitado históricamente el contacto a distancia entre las personas. Las TIC, como productos de un proceso complejo y en constante cambio, se han diversificado en nuevas formas como Internet, los e-mails, el chat, Skype ${ }^{2}$, los teléfonos celulares. Las TIC, como nuevos medios y/o artefactos culturales ${ }^{3}$, potencian y cambian los usos y las mediaciones ${ }^{4}$ que las personas les daban a los artefactos pasados.

Dentro del campo de los estudios migratorios, diversas investigaciones (Peñaranda Cólera, 2008 y 2010; Gonzálvez Torralbo, 2012; Mejía Estévez, 2005; Winocur, 2010, entre otros) coinciden en que el teléfono es el primer artefacto tecnológico utilizado por los migrantes para conectarse con sus familias. El segundo artefacto utilizado es Internet. Desde la World Wide Web pueden contactarse con su núcleo familiar, buscar información, participar y crear webs diaspóricas, conectarse con sus connacionales en cualquier parte del mundo, etcétera.

La apropiación de estas tecnologías hace que la circulación de información y la comunicación entre personas sean mayores, de menor costo y más rápidas. Si bien, la apropiación y uso de las nuevas tecnologías de la información y de la comunicación como Internet representan un abanico de frondosas posibilidades para la conexión, comunicación y expresión por parte de los diversos colectivos migratorios, esta experiencia (de apropiación) no es nueva. Por ejemplo, centrándonos en el campo de la comunicación, los grupos migratorios en la Argentina han utilizado desde finales del siglo XIX a la prensa escrita comunal ${ }^{5}$ como medio de expresión y de circulación de saberes, de valores y de expectativas de cada grupo. En la actualidad los usos y apropiaciones de saberes que tienen que ver con el universo del periodismo conviven con el uso de los sitios web, de las comunidades virtuales o de Facebook.

Como ya señalamos, las TIC generan nuevas formas de organización social o transforman las existentes. En este sentido, nos proponemos discurrir acerca de la apropiación y uso de las TIC por parte de las comunidades de migrantes andinos en la Argentina y su convivencia con otras prácticas de expresión y comunicación establecidas en dichas comunidades

1 Si bien se podría realizar una distinción entre las Nuevas tecnologías de la información y la comunicación y las más antiguas o tradicionales, utilizaremos genéricamente TIC para englobar a todas ellas.

Software que permite hacer llamadas o video-llamadas gratuitamente desde cualquier ordenador.

Artefactos que adquieren en el uso (contexto) significaciones culturales diversas.

4 Las mediaciones son espacios, formas de uso y apropiación de los bienes culturales producidos por las clases dominantes por parte de las clases subalternas. Las clases subalternas ponen en juego sus raíces culturales (conocimientos, saberes, valores, sentidos e imaginarios) a la hora de recepcionar y resignificar aquello (tanto un mensaje como tecnología) proveniente del bloque esfera hegemónico (Martín Barbero, 1991).

5 Utilizamos prensa o periódicos comunales, étnicos, migrantes como sinónimos para referirnos a las publicaciones gráficas emitidas por las colectividades o grupos migratorios. 
como los periódicos de inmigrantes. Hemos seleccionado dos colectividades andinas con gran arraigo en la Argentina como la boliviana y la peruana. Estas dos comunidades poseen periódicos étnicos desde la década de los noventa y recientemente han sumado el uso de las TIC a su edición en papel. Es importante subrayar que cada una de estas colectividades elegidas ha sido objeto de discursos y de prácticas discriminatorias y xenófobas y que su existencia se ha vinculado siempre al lugar del subalterno. En este sentido, creemos que es central preguntarse no sólo por la apropiación y uso de las TIC -en este caso Internet- de los colectivos migratorios en general sino cómo influye en la construcción identitaria. Nos basamos en una metodología cualitativa que contempla el análisis de discurso planteado por la semiótica contemporánea, en especial en la propuesta por los semiólogos argentinos Steimberg y Traversa (1993). Consideramos a los periódicos, y a los sitios Web como textos que contienen ciertas marcas o rasgos de tipo retórico, temático y enunciativo plausibles de ser detectados por el analista. Estos rasgos nos permiten dar cuenta del estilo de estas publicaciones y corresponden el insumo sobre el que construimos nuestra base interpretativa sobre la construcción de la identidad de cada grupo migratorio ${ }^{6}$.

\section{Identidad, globalización y tecnología}

La sociedad de la información o sociedad red está caracterizada por la globalización de actividades económicas, por la flexibilidad, inestabilidad e individualización del trabajo, por la presteza de los Estados nacionales, por la cultura de la virtualidad real construida por un sistema de medios de comunicación omnipresentes, interconectados y diversificados y por la transformación de los cimientos materiales de la vida (espacio y tiempo) mediante la constitución de un espacio de flujos y del tiempo atemporal (Castells, 1999). Esta forma de organización social se propaga en todo el mundo. Sin embargo, lo que diversos autores (Bauman, 1999, 2003 y 2005; Castells, 1995 y 1997; Hopenhayn, 2001; Huyssen, 2002; Sassen, 2005, entre muchos otros) han catalogado como una de las paradojas de estas sociedades modernas radica en que la contracara de la globalización imperante (lo global) parece ser el repliegue de porciones de estas sociedades hacia la esfera de la identidad (lo local). La pérdida de presteza de los Estados nacionales y la reconfiguración del capitalismo han dado como resultado un aumento en las expresiones de identidad colectiva que afrontan a la globalización en nombre de la singularidad cultural. Sin embargo, como apunta Martín Hopenhayn (2001), lejos de ser expresiones netas de prácticas de resistencia (aunque no quiere decir que no lo serán, como desarrollaremos más delante), la singularización, la diferenciación, la localidad -que tienen que ver con lo identitario y con la prevalencia de un nosotros frente a un otros- también se han masificado. La personalización de cada uno se empalma bajo la matriz identificatoria global. En este sentido, la cultura de masas y la tribalización posmoderna no se excluyen sino que son constitutivas una de la otra. Y esto no se debe a que la cultura disruptiva se hace masiva sino a que la masa se torna discontinua (en clara consonancia con el modo de ser

6 Ampliaremos en el apartado metodología. 
diversificado de las nuevas TIC). Esta liberación de las diferencias coincide con la irrupción de identidades que habían permanecido periféricas.

En este escenario, los medios de comunicación y las TIC son espacios de expresión y de conformación de estas identidades (desde el fundamentalismo islámico, hasta los movimientos democráticos en África o las luchas de las "minorías"). Entendemos a las identidades como construcciones discursivas, históricas y relacionales en las que se ponen en juego valores, sentidos, imaginarios de determinados individuos, comunidades, grupos sociales, etcétera (Arfuch, 2002; Grimson, 1998; Cardoso de Oliveira, 1999; Bauman, 2005; Hall, 2003, entre otros).

Las identidades son fuentes de sentido de los propios actores, son procesos de individualización (fuentes de sentido, la identificación simbólica que realiza un actor, dice Castells) que no necesariamente tienen que ver con las instituciones aunque se pueden originar en ellas. Una característica de las sociedades contemporáneas es que las identidades han dejado de construirse primariamente en el seno de las instituciones y de la sociedad civil (identidades legitimadoras) ${ }^{7}$ sino que lo hacen desde el plano de la cultura y como resistencia a la homogeneización de la globalización (resistencia comunal). La red de redes se conforma como espacio y como artefacto para la conformación de identidades que, lejos de borrar las categorías tradicionales de su conformación (raza, sexo, nación, etcétera), las reformulan.

\section{Apropiación y construcción de identidades. Primeros interrogantes}

Hace unos años la investigadora argentina Beatriz Sarlo se preguntaba ¿qué hacía la gente con lo que veía en los medios de comunicación? Hoy, las TIC y las facilidades que proporcionan (velocidad, reducción de distancias, menor costo, visibilidad y capacidad de producir y emitir contenido de una forma más fácil y práctica) nos ahondan ese interrogante. Más allá de ser nuevos medios tecnológicos, proporcionan un espacio de negociación y de mediación por parte de los usuarios (productores) en el que se pueden desarrollar nuevas prácticas que involucren, por ejemplo, a la conformación de discursos identitarios.

Las poblaciones migrantes se han apropiado de las tecnologías para superar las distancias y construir nuevas formas de relación con la comunidad de origen y destino. Las TIC han permitido mantener más fluidos los círculos afectivos y relativizar la ruptura causada por la lejanía. Las TIC han potenciado la conformación de una doble presencia: la física (o real) y la imaginada (o virtual), la de estar aquí y allá pudiendo participar en la comunidad de origen y en la de destino (tornando estas

\footnotetext{
Castells (1999) distingue tres formas de construcción de la identidad: 1) Identidad legitimadora: introducida por las instituciones dominantes; 2) Identidad de resistencia: generada por actores que se encuentran en posiciones devaluadas o subalternas en relación a las lógicas de dominación (trincheras de resistencia); 3) Identidad proyecto: los actores sociales construyen una nueva identidad que redefine su posición en la sociedad y busca la transformación de la estructura social. Las identidades que comienzan como resistencia pueden devenir en proyecto.
} 
diferenciaciones cada vez más caducas). Esta doble presencia, que también ha sido denominada presencia conectada (Diminescu, 2011; Locoppe y Smoreda, 2005) inaugura "una nueva modalidad de presencia, a pesar de la distancia física, posibilitada y facilitada por un patrón continuo de interacciones mediadas por las TIC” (Peñaranda Cólera, 2008: 147).

Entonces, si bien podemos afirmar que de modo general las TIC han transformado las prácticas dentro de los procesos migratorios, la pregunta es cómo, de qué modo, han sido apropiadas las TIC en esos colectivos. ¿Cuáles son las experiencias y prácticas culturales que se generan como consecuencia de la incorporación de las TIC en la vida cotidiana de los colectivos migratorios, como por ejemplo en su prensa? ${ }^{8}$

Entendemos, siguiendo a Rosalía Winocur, a la apropiación como un “... conjunto de representaciones y prácticas socioculturales que intervienen en el uso, la socialización y la significación de las nuevas tecnologías en diversos grupo socioculturales (Winocur, 2007: 191). El uso de la tecnología no implica la mera relación con el objeto sino que implica la relación con un universo de representaciones culturales (técnica) con las que esa tecnología se articula. Usar Internet es una apropiación práctica e interpretativa (Cabrera citado por Winocur, 2007).

La apropiación de Internet (artefacto cultural ${ }^{9}$ ) en las prácticas cotidianas de construcción de un discurso identitario por parte de los colectivos migratorios andinos en la Argentina a través de su prensa implica generar nuevas tácticas (en términos de De Certeau ${ }^{10}$ ) o mediaciones (en términos de Martín Barbero) para la conformación y la circulación de ese discurso. La computadora y las TIC son un recurso estratégico para mejorar la comunicación y conectividad con sus connacionales, con la sociedad receptora y con sus países de origen. En este sentido Internet es un espacio para la producción propia que no depende netamente de los grandes conglomerados de comunicación (medios hegemónicos). Este acceso a la información y la posibilidad de producir información, podría, desde un plano instrumental, abrir formas de intervención cívica, cultural y política.

8 En el siguiente apartado analizaremos una experiencia en particular que es la apropiación y el uso de las TIC por parte de los periódicos de migrantes de la colectividades boliviana y peruana en la Argentina y su injerencia en la conformación de un discurso identitario.

9 En este sentido, retomando los planteos de Christine Hine (2004), concebimos a Internet como artefacto cultural que adquiere significados culturales y usos diferentes en relación a los contextos donde es utilizado. Sin embrago, el uso de Internet permitirá la creación de una cultura o de un discurso cultural. El ciberespacio también es entendido como un lugar donde se gesta una cultura, un espacio de pleno derecho. La tecnología tiene significados culturales diferentes según los contextos en que es empelada (por ejemplo, las formas de construir información de los periódicos de los colectivos migratorios como el caso de Renacer son la base para el uso que este periódico le da a su dominio de Facebook, y esta utilización excede las posibilidades instrumentales que provee el sitio). Para relacionarse con internet se ponen en juego conocimientos que ya se tienen: los mundos on line y off line se conectan de manera compleja.

10 Para De Certeau (1996) ante la imposición de una determinada estrategia (manipulación de las relaciones de fuerza por parte de un sujeto de poder que se basa en la imposición de un lugar como propio) por parte de la cultura dominante (del ellos), la cultura popular responde a través de tácticas (prácticas que al estar determinadas por la ausencia de poder no poseen más lugar que el de la estrategia razón por la cual que dependen de los azares del tiempo para poder funcionar). 
Sin embargo, la concreción de esas prácticas no depende puramente de factores técnico-instrumentales sino que es central la importancia dada a la comunicación (Benítez Larghi, 2010). Los sectores subalternos como los migrantes se apropian de las TIC de determinada manera (tácticas) y en pos del cumplimiento de determinados objetivos, anhelos, deseos y necesidades. Por ejemplo, en el caso de los periódicos de las colectividades migrantes presentes en la Web (sitios on line y Facebook), si bien utilizan las herramientas brindadas por Internet (estrategias), hacen uso de ellas para difundir su discurso, que en muchos casos genera una alternativa a los discursos dominantes de los grandes conglomerados mediáticos (por ejemplo, la convocatoria a actividades culturales de los pueblos indígenas, el primer festival de cine indígena en la Argentina durante 2012, la denuncia del asesinato de personas pertenecientes a la comunidad indígena Qom, la convocatoria al voto de los ciudadanos peruanos en el exterior o abrir debates sobre la Ley 26.522 de Servicios de Comunicación Audiovisual de la Argentina que amplía la posesión de medios a entidades comunitarias y minorías).

Desde esta óptica, podíamos leer los discursos que circulan en las ediciones Web de los periódicos de las colectividades migrantes andinas citadas como un ejemplo de resistencia comunal (Castells, 1995). Esta resistencia, cuyo eje pareciera ser la construcción de las identidades, va de la mano de las prácticas de los subalternos en las cuales la apropiación tiene un papel fundamental. En nuestro caso de análisis los interrogantes que surgen a la luz de estas prácticas son: ¿qué papel cumplen las TIC y los medios de comunicación en las prácticas de los subalternos?

Y más específicamente, ¿¿cuál es el uso o la injerencia de las TIC en la construcción de un discurso por parte de los colectivos migratorios andinos? ¿Ahondan las posibilidades de visibilidad y de construcción de un discurso alternativo? ¿Pueden esas identidades construidas desde la resistencia comunal disputar entidad en el espacio simbólico a las representaciones hegemónicas? Nuestra conjetura es que las TIC juegan un papel importante al poder ser apropiadas y funcionan como medios/mediaciones para la construcción de identidades y de discursos alternativos (valores alternativos y/o contrahegmónicos).

Específicamente en el campo migratorio, pensamos que las TIC toman el lugar y lo reestructuran de otras prácticas (de apropiación) comunicacionales por parte de las comunidades migrantes como, por ejemplo, la emisión de una prensa comunal o migrante.

\section{Metodología y objeto de estudio}

Para realizar un análisis de los periódicos planteamos una metodología cualitativa que parte de considerar a los periódicos en su versión papel, digital y la plataforma de Facebook como discursos sociales ${ }^{11}$. Según el semiólogo argentino Eliseo

\footnotetext{
11 Siguiendo los criterios de Verón nos abocamos a realizar un estudio de la producción mediática y discursiva de los colectivos, si bien creemos fundamental un análisis de las audiencias, este tipo de estudio excede con creces el propósito de este artículo.
} 
Verón (1993) los discursos se transforman en textos a partir de un proceso de cristalización de éstos por parte del analista. Éste último debe analizar pequeños fragmentos del tejido de la semiosis social. Verón (1993) concibe a los fenómenos de sentido como conglomerados de materias significantes remitentes a una red semiótica conceptualizada como sistema productivo (dimensiones de la producción, circulación y consumo o reconocimiento).

El discurso es un punto de pasaje, un encuentro entre las relaciones de producción y de reconocimiento de los fenómenos de sentido. La posibilidad de este análisis de sentido radica en que el sistema de producción deja huellas (marcas) sobre los productos (textos) y que esas operaciones pueden ser reconstruidas a partir del análisis de los primeros. Entonces, la diferencia entre texto y discurso reside en que el primero se encuentra recortado de la red semiótica para ser estudiado por el analista. Sobre esta base, optamos por una metodología cualitativa que contemple el análisis de discurso y de contenido a partir de las herramientas propuestas por la semiótica contemporánea.

Partimos de la descripción de las dimensiones retórica, temática y enunciativa propuestas por los investigadores argentinos Oscar Steimberg y Oscar Traversa $(1993,1997)$ que nos permite dar cuenta de las características distintivas del texto. Según esta tipología todo texto está compuesto por estas tres dimensiones (retórica o figural, temática y enunciativa) que reflejan su modo de hacer, su estilo. La superficie retórica está compuesta por los elementos esenciales que definen la estructura del texto que permiten diferenciarlo de otros. La dimensión temática contempla elementos previos y exteriores al texto (no se corresponden necesariamente con el contenido específico). La enunciación es el efecto de sentido de un texto (presenta posteriormente al análisis de los rasgos temáticos y retóricos).

La portada de un periódico o la página de un sitio Web imponen, desde su diseño gráfico, un orden, una cohesión, una forma de presentarse ante los posibles lectores, una identidad, un estilo. Características como 1) estrategias gráficas y uso del color, 2) presencia de fotografías, 3) publicidades, 4) uso y diagramación del espacio, 5) presencia de logotipo, son las estrategias discursivas que a nivel retórico configuran la primera plana de los periódicos y sitios Web que hemos tenido en cuenta para abordar estos textos. Para abordar la dimensión temática clasificamos los titulares de los sitios a partir de los siguientes tipos de información: 'político', 'policial', 'económico', 'deportes', 'cultura y espectáculos'. Estos tipos son la expresión de diversas temáticas que atraviesan la publicación: 'discriminación y xenofobia', 'religiosidad', 'indigenismo', 'ampliación de derechos' (políticos, civiles y sociales, como por ejemplo el derecho al voto, el derecho a la información, los derechos laborales, entre otros) y 'las políticas migratorias'. Por último, como mencionamos antes, la dimensión temática y retórica configuran la enunciación de cada sitio que conforma un contrato de lectura con los destinatarios potenciales. Este contrato da cuenta de la relación entre un soporte y su lectura, motivo por el que su análisis permite determinar la especificidad de un soporte, es decir, las estructuras enunciativas a partir de las cuales el contenido es presentado por el medio en cuestión.

Así, en primera instancia, nos avocamos al análisis de los discursos emitidos por estos migrantes en la Web y relevamos los cambios acaecidos en las tres dimensiones descriptas durante un período de seis meses para cada publicación y esta- 
blecimos comparativamente cambios y continuidades que nos sirvieron de base para la etapa interpretativa sobre la construcción de identidades. Hemos elegido dos publicaciones (Renacer de la colectividad boliviana y Gaceta del Perú de la peruana) porque son las más antiguas emitidas por cada colectivo (ambas datan de la década del noventa). Los bolivianos y los peruanos son las comunidades de países andinos más arraigadas en la Argentina (a excepción de los chilenos). Cuentan con instituciones civiles, asociaciones culturales, con emprendimientos comerciales de carácter étnico y con varios medios de comunicación como radios, periódicos y sitios Web (Melella, 2012 y 2013).

Por último, si bien este artículo se centra en el análisis de discurso y contenido de las producciones mediáticas creadas por estos grupos, también hemos tenido en cuenta la experiencia de los directores y Webmaster de los sitios como Emilio Calderón de Gaceta del Perú y Guillermo Mamani de Renacer.

\section{Los colectivos migratorios andinos en la Argentina. De los periódicos étnicos al uso de Internet}

La Argentina creció en el siglo XIX a la luz de la llegada de miles de inmigrantes europeos. Más allá de trabajar o de formar familias, muchas de sus actividades se enfocaron en desarrollar el encuentro social entre connacionales en la nueva tierra. La prensa gráfica de migrantes fue una consecuencia directa de la floreciente vida comunitaria (Devoto, 2007). Estas publicaciones tuvieron cuatro funciones principales: constituirse como medio solidario y de información, medio de expresión y de participación cívica alternativa, lazo de cohesión interna y de visibilidad y, por último, espacio de construcción de identidades (Baravalle, 2007; Garabedian, 2011; Oteiza, 2010; Melella, 2012).

La migración de países andinos, si bien no es un fenómeno reciente, ha adquirido con los años una mayor visibilidad. La migración boliviana a la Argentina se inició hacia finales del siglo XIX y durante la última década, nuestro país se convirtió en el primer destino de esta población (Sassone, 1994, 2002 y 2009; Benencia, 1995, 2008, entre otros). La migración peruana es posterior, comienza a incrementarse a partir de la década del cincuenta del siglo pasado y tiene su auge en la década del noventa cuando Perú sufre una importante depreciación económica (Altamirano, 2003 y 2010; Macchiavello, 2009; Lapenda, 2010; Pacceca, 2009, entre otros).

Los colectivos migratorios andinos de más arraigo como los bolivianos y peruanos han fundado sus periódicos (en la década del noventa) como respuesta ante los discursos estigmatizantes de la prensa hegemónica nacional que los vinculaba como causantes de enfermedades, de la desocupación y de la delincuencia imperantes en aquellos años (Casaravilla, 1999; Caggiano, 2005; Courtis, 2005; Castiglione, 2006; Halpern, 2007, entre otros). Los dos periódicos más antiguos de estos grupos migratorios son: Renacer de la colectividad boliviana y Gaceta del Perú de la comunidad peruana. Estas publicaciones se emiten en la actualidad y han pasado al formato digital y al uso de redes sociales virtuales como Facebook y Twitter, lo que brinda nuevas formas de comunicación y de conexión traspasando los límites espacio-temporales humanos. 
El periódico Renacer nació en Buenos Aires en el año 1999 con el objetivo de alzar la voz de los inmigrantes bolivianos residentes en la Argentina frente a las acusaciones expuestas en los medios masivos de comunicación locales que relacionaban a los trabajadores pertenecientes a esa comunidad como la principal causa del progresivo aumento de la desocupación y del desempleo. Su director es Guillermo Mamani, Licenciado en Ciencias de la Comunicación por la Universidad de Buenos Aires. La edición Web del tabloide expone: "El periódico Renacer nació en 1999, en la ciudad de Buenos Aires en plena "caza de brujas" cuando funcionarios del gobierno argentino y medios de comunicación adeptos, impulsaron una campaña a la opinión pública; responsabilizando a los migrantes por el aumento en la desocupación y en el desempleo" (www.renacerbol.com.ar).

Actualmente Renacer tiene un costo aproximado de cinco pesos y posee una tirada de diez mil ejemplares. Se financia con la venta de publicidad y suscripciones. Consta de varias secciones entre las que se destacan: Bolivia, Actualidad, General, Editorial, La ciudad, Deportes, Cultura, Regionales, Interior e Internacional. Además, cuenta con un staff de una decena de redactores que trabajan desde sus oficinas en el Barrio Charrúa (emblemático para la colectividad boliviana en Buenos Aires) y más de diez colaboradores situados en diversos departamentos de Bolivia como La Paz, Tarija y Oruro. También tiene corresponsales en Mar del Plata y en las provincias argentinas de Mendoza, Chubut y Neuquén.

Renacer es un medio de comunicación alternativo ${ }^{12}$ a los medios hegemónicos ya que no sólo brinda cierta información que no es tenida en cuenta por la agenda de los grandes medios, sino que también discute y critica las posiciones políticas e ideológicas tomadas por los medios de gran tirada en torno a cuestiones centrales que muchas veces exceden a los intereses de la misma colectividad. Renacer arguye sobre la discriminación y la xenofobia, la estigmatización del colectivo boliviano en la Argentina pero también acerca de los derechos de los pueblo indígenas, del derecho a la expresión y a la comunicación, etcétera.

La Gaceta del Perú se edita en la Ciudad Autónoma de Buenos Aires desde el año 1991. Su director es el periodista Emilio Calderón. La emisión de la Gaceta tiene una frecuencia semanal y se distribuye gratuitamente en espacios que tienen que ver con la peruanidad (restaurantes étnicos, el Consulado Nacional del Perú, la Embajada de Perú en la Argentina, locutorios, etcétera). Se entrega en la Ciudad Autónoma de Buenos Aires (CABA), Gran Buenos Aires y ciudades del interior del país como Rosario y Mar del Plata. La Gaceta surgió en un año atravesado por dos hechos importantes para la comunidad peruana: el rebrote del cólera en las provincias del norte argentino (y su vinculación directa con los inmigrantes limítrofes y por extensión a migrantes andinos ${ }^{13}$ ) y las acciones terroristas de Sendero Luminoso en el Perú. Según Calderón,

12 Entendemos, junto a Vinelli y Rodríguez Esperón (2004) que los medios alternativos no se definen solamente por los rasgos que adquiere la práctica en su desarrollo sino que el elemento determinante es la dependencia de un proyecto de cambio radical de la sociedad.

13 Halpern (2007) sostiene que durante la década del 90 hubo tres escenarios que vincularon a los inmigrantes regionales con discursos discriminatorios: El reconocimiento mediático del cólera en la Argentina, masivamente expuesto en febrero de 1992; el crecimiento 
frente a la vinculación de los peruanos a estos dos hechos dotados de una alta carga de negatividad, hacía falta que se escuchase la voz de este colectivo en la Argentina. En palabras de Emilio Calderón:

"Hubo dos problemas: en un momento había habido una enfermedad, cólera y Sendero Luminoso estaba en su pleno apogeo. Entonces eran dos cosas que había que contrarrestar, como una explicación al pueblo argentino, por eso le pusimos 'una voz peruana para la hermana Argentina', pero no seguimos usando ese slogan. La idea era eso: explicar. Y de ahí surgieron otras cosas, comentar que estaban haciendo las instituciones. Me acuerdo que en el primer diario decíamos qué hacían las Damas Peruanas acá (...) El comienzo era un poco cultural porque no había muchas noticias de los peruanos. Había que poner noticias del Perú, pero después era un poco diferente porque no teníamos tampoco Internet. Teníamos que esperar el diario de Perú, buscar las noticias, era otra cosa. Tocábamos muchos temas de acá de Argentina" (Entrevista realizada a Emilio Calderón).

El periódico cuenta hoy con más veinte años de trayectoria y una distribución semanal que varía entre 2500 y 5000 ejemplares. Si bien en la actualidad la función de director, editor y periodista la cumple en su mayor parte Emilio Calderón, la Gaceta ha contado con un staff de colaboradores.

En cuanto al financiamiento, nunca ha recibido colaboración de ningún organismo oficial ni de la Argentina ni del Perú. Tampoco lo han patrocinado organizaciones culturales o sin fines de lucro. En un principio surgió como una empresa comercial aunque luego resultó que los periódicos se entreguen gratuitamente. Hoy la Gaceta se financia solo por la venta de espacios para publicidad.

A grandes rasgos y basándonos en la categorización analítica descrita en el apartado metodológico, podemos establecer que ambos periódicos mantienen (en un nivel retórico o figural) rasgos que los acercan al universo simbólico de la bolivianidad y de la peruanidad como, por ejemplo, presencia de sus banderas nacionales (o de sus colores), fotografías de miembros de la colectividad o de acontecimientos en los países de origen, simbología relacionada con el universo andino y /o indígena (monumentos como la Flor de Kantuta, la Wiphala o Puerta del Sol en Bolivia o Tumi incaico) y publicidades de comercios típicos de la comunidad (restaurantes, empresas de envío de dinero, comercios vinculados con la industria de indumentaria, o agencias de viajes, entre otros) ${ }^{14}$.

Desde una dimensión temática, en la agenda de ambos periódicos hay una fuerte presencia de las noticias de sus países de origen y de los sucesos de cada colectividad en la Argentina. Asimismo, en la agenda periodística priman las noticias

exponencial de la desocupación en el país y que llegara al 18\% en 1994 y el reconocimiento masivo y mediático de una supuesta crisis de seguridad urbana en la Ciudad de Buenos Aires, a comienzos de 1999.

14 No nos explayaremos en el análisis de la prensa gráfica de migrantes andinos sino que nos abocaremos más al pasaje hacia la Internet. Para un panorama más amplio sobre el tema ver: Melella, C. (2011). La prensa migrante como recurso de visibilidad y construcción de identidades. El periódico Renacer, de y para la colectividad boliviana en la Argentina; Melella, C. (2012). La prensa migrante peruana en la Argentina: el caso de la Gaceta del Perú. 
políticas, seguidas por las de cultura y espectáculos, deportes, policiales e información general. Los dos periódicos cumplen la función de servicios al informar acerca de la tramitación migratoria, de los derechos de los trabajadores, del ejercicio a voto en el exterior.

También los dos brindan información acerca de las culturas originarias, aunque Renacer se ha posicionado como un defensor y comunicador de los derechos de los pueblos originarios (derecho a tierras, a la comunicación, a la diversidad cultural, etcétera). Gaceta del Perú, desde un perfil más comercial, se preocupa por fomentar la solidaridad y el sentimiento de comunidad en el colectivo peruano en la Argentina por medio de campañas solidarias. Asimismo, son centrales las notas de opinión de su director Emilio Calderón. Por último, debemos señalar que un eje editorial importante en los dos periódicos es la denuncia de prácticas xenófobas y discriminatorias de las que son y han sido objeto estos grupos migratorios en nuestro país.

Finalmente, ambos periódicos se construyen como discurso periodístico clásico cuyo objetivo primordial es la información (ni el enunciador ni el enunciatario están explícitamente marcados y, según Verón, se designa un contrato donde un enunciador objetivo e impersonal habla la verdad). Sin embargo, en ambos casos hay cierto grado de complicidad entre el enunciador y el destinario basado en el conocimiento de ciertos saberes, sentidos y códigos comunes. Si bien el discurso periodístico, cuyo objetivo es informar, implica el contrato complementario y distante, la complicidad es más significativa que en otras publicaciones de la prensa gráfica ordinaria; se acentúan los efectos de referencialidad y propone complicidad con el destinatario, y la referencia a los espacios son fundamentales para construir esa complicidad (tanto en el nivel retórico o figural como temático $)^{15}$.

\section{Resultados. La apropiación y uso de las TIC en el universo de la prensa migrante en la Argentina. Los casos de Renacery la Gaceta del Perú}

A partir de lo anterior, de manera sucinta, podemos señalar que estos dos periódicos de migrantes también pueden ser caracterizados bajo las funciones centrales de los periódicos de principios de siglo pasado: Como medios solidarios y de

15 Tanto Renacer como la Gaceta del Perú desarrollan cierta construcción de la identidad (identidades) de los bolivianos y peruanos en la Argentina: es decir, un nosotros y un otros/ellos. El estudio de las configuraciones textuales (dimensión retórica, temática y enunciativa) de ambos periódicos posibilitó el abordaje del discurso identitario de ambos colectivos migratorios y nos permitió dar cuenta de sus representaciones político-culturales, de sus prácticas y de las tensiones con la sociedad receptora y hacia adentro del mismo colectivo. Debido a la extensión de este trabajo no desarrollaremos la construcción de las identidades aquí ya que nuestro objetivo principal es reflexionar sobre el uso de las TIC por parte de los periódicos en cuestión. No obstante, de manera sucinta podemos señalar que el periódico Renacer construye diversas identidades de los bolivianos en Argentina que versan sobre cuatro núcleos centrales como el nacionalismo, la apelación al indigenismo, la condición de inmigrante/extranjero, así como el ejercicio de los derechos políticos. La Gaceta del Perú, construye su identidad también sobre su condición de inmigrante/extranjero, sobre el nacionalismo y sobre el sentimiento de comunidad. 
información; medios de expresión y participación cívica alternativa; como recursos de conformación de identidades y como conformadores de lazos de cohesión interna y visibilidad. En este sentido, cabe preguntarse ¿qué cambios, qué caminos o nuevas posibilidades se despliegan en el pasaje de estos periódicos a la red virtual?

\subsection{Renacer on line}

La página de un periódico digital como Renacer no se actualiza diariamente como sí lo hacen los grandes diarios on line de tirada masiva como Clarín o La Nación. Su edición digital tampoco tiene tantos recursos y aplicaciones como las de aquellos periódicos (estado del tiempo, acceso directo a Facebook, Twitter, Google, Printerest, Rss, publicidad interactiva, etcétera).

Renacer traslada a la Web la misma edición que publica en papel. Un dato curioso es que este sitio no se actualiza desde octubre de 2011 (aunque se pueden revisar las ediciones anteriores desde el número 100 de septiembre de 2005). Esta situación nos marca que el diario en papel (y el pasaje a Facebook ${ }^{16}$ ) sigue siendo más importante que la edición virtual (puede ser debido a la persistencia de la suscripción en papel, la imposibilidad de acceso a las nuevas tecnologías por parte de algunos de sus lectores, o por la incidencia del dominio en Facebook).

Desde un plano retórico y temático, la edición on line mantiene ciertas características de la publicación gráfica: el uso de colores referentes a la bandera boliviana, la inclusión de fotografías o de simbología andina (flor de Kantuta, Puerta del Sol, Wiphala) o las publicidades que representan espacios vividos y prácticas llevadas a cabo por esta colectividad (transportes de larga distancia, courrier de envío de dinero al exterior, restaurantes étnicos).

Asimismo, la elección de los temas responde a un público vinculado a la comunidad boliviana en la Argentina: política de Bolivia y de Argentina, eventos culturales y de espectáculos, noticias sobre instituciones y comunidades, indigenismo, denuncia de la discriminación y la xenofobia, información sobre derechos políticos, civiles y sociales de los migrantes o residentes. Sin embargo, como señalamos anteriormente, la pertenencia a la colectividad no pareciera ser una característica determinante ya que Renacer incluye otras temáticas que la exceden como los derechos de los pueblos indígenas, el apoyo a una política latinoamericanista que concibe a los países de América Latina como una "patria grande", entre otras.

Desde un plano instrumental-tecnológico Renacer on line propone entradas interactivas para recibir la gacetilla virtual o para suscribirse y recibir el diario de papel en su domicilio. También promociona su presencia en Facebook. Asimismo, este formato provee otras posibilidades como la inclusión de links u otros sitios, de chat y de un foro. Una forma de comuni-

16 Asimismo habría que ver la incidencia del uso de Facebook de Renacer, ya que este último cuenta con más de 5000 amigos y más de 1000 suscriptores (lo que nos daría un total de 6000 personas) comparable a nivel de la recepción y circulación con los lectores hipotéticas tirada de 10.000 ejemplares de gráfica. 
cación como el chat supone que las partes estén presentes, en el foro, en cambio esto no es necesario. Estas nuevas formas comunicativas nos hablan de la capacidad de horizontalidad de la red virtual.

Por otra parte, el sitio on line también es un medio donde no solo se construye identidad (de la comunidad boliviana en la Argentina) sino que esa construcción trasciende a un nivel internacional y/o transnacional. Se reconocen como bolivianos en la red donde la esfera espacio-temporal ya no es central. Las relaciones rastreadas por medio de los links nos denotan contactos más allá de las fronteras (relaciones con asociaciones de bolivianos globales).

No obstante, la publicación de Renacer on line no deja de ser un periódico, uno de sus objetivos centrales sigue siendo informar y, más allá de la horizontalidad que propone la red virtual, prolonga una forma vertical. En este sentido, el contrato pedagógico ${ }^{17}$ sigue prevaleciendo y el periódico continúa siendo un nexo (lazo o nodo) entre los individuos -lectores-y la información (punto-masa).

\subsection{Gaceta del Perú en Facebook}

El periódico Gaceta del Perú no cuenta con edición digital en funcionamiento pero sí posee un dominio en Facebook. Una plataforma como Facebook, al igual que las páginas Web, enfatiza esta propiedad de transparencia de la red, por ejemplo, a través del Protocolo Open Graph ${ }^{18}$. También tiene la opción "amigos en común” mediante la cual uno puede saber qué "contactos" o "amigos" comparte con otros (lazos).

A partir de la entrada al Facebook de la Gaceta del Perú podemos reconstruir la red al identificar sus contactos o "amigos". Podemos tipificar los "amigos" en tres: Comunidades, periódicos y/o medios de comunicación e individuos. Si tomamos como referencia julio de 2012, el sitio de Facebook tenía un total de 846 “amigos" de los cuales 96 no eran personas físicas sino comunidades o instituciones. De esas 96, 11 eran medios de comunicación y 3 periódicos de migrantes -peruanosen la Argentina (Cholo con Che, El Heraldo del Perú y Sol del Perú).

Estos tres periódicos, a su vez, se relacionan entre sí, pero no establecen con frecuencia links en común con la Gaceta del Perú, con la excepción de festividades que engloban a toda la colectividad como "Feria Cultural Perú", realizada en la Plaza Perú de Buenos Aires en noviembre de 2012 y auspiciada por el Gobierno de la Ciudad de Buenos Aires. También entre los

17 En el contrato pedagógico el enunciador y el destinatario se encuentran en una relación asimétrica.

18 Por ejemplo, el Protocolo Open Graph habilita la interacción de cualquier sitio Web con Facebook. Esto es: a través de una integración sencilla el sitio se "transforma" en un "objeto" de Facebook, por lo cual, los usuarios se pueden suscribir al sitio a través de la aplicación "me gusta” y éste les podrá mandar actualizaciones automáticas. Lo interesante es que los administradores de estos nuevos sitios pueden acceder a las estadísticas de su comunidad para monitorear el comportamiento de los suscriptores. Los sitios y aplicaciones sociales que utilicen este protocolo pueden acceder al grafo social, es decir, a información, gustos e intereses de los usuarios y compartirlo con los demás (López y Ciuffoli, 2012). 
tres diarios comparten muchos "amigos" como asociaciones, grupos de baile, restaurantes, instituciones oficiales de la colectividad. Esta confluencia remite a una red virtual que reproduce y/o se superpone con una real.

Asimismo, Facebook también potencia la instantaneidad y la interacción de las páginas Web con una estructura nula (sólo hay que utilizar gratuitamente la aplicación). En este sentido, el contacto en tiempo real favorece a quienes se encuentran alejados por una gran distancia. En el caso de los migrantes, la principal función pareciera ser el contacto con la familia, pero también es posible fomentar el vínculo con otros connacionales que se encuentran en otros países, potenciar la circulación de información o la concreción de negocios.

Además, Facebook permite "subir o postear" información (fotos, textos, video, links) de una forma más sencilla e instantánea. También existe la opción "compartir" la información que haya subido un "amigo", y lo interesante es que expone de quien uno ha obtenido esa información (reconstruye la red). En este sentido, el proceder de la Gaceta del Perú es paradójica porque, como señalamos antes, habitualmente "sube" su propia información a la red (al muro) y escuetas veces "comparte" o publica información de otros "amigos".

También, señalamos que la Gaceta del Perú se relaciona más con personas individuales y no tanto con otros medios (tiene más “amigos" individuos). Por consiguiente, la Gaceta del Perú en Facebook sigue las normas establecidas por el periodismo en general y de la prensa gráfica en particular cuya misión es informar: no linkea, no comenta, sino que informa creando su propio contenido (aunque esto implique recortar los paratextos de las noticias levantadas de otros medios o editarlas, les pone el sello de la Gaceta).

Desde lo retórico o figural reproduce la lógica del periódico en papel (por ejemplo, representaciones incaicas). Los temas que abarca se centran en las actividades de los peruanos en la Argentina (celebraciones patronales, eventos solidarios, noticias institucionales) y las noticias del Perú. Como en la publicación gráfica es muy importante la inclusión de notas de opinión sobre diversos temas firmadas por Emilio Calderón.

\section{Conclusiones. Prensa gráfica y TIC: diferencias y continuidades}

El pasaje de los periódicos de migrantes a distintas plataformas de la red social virtual como páginas digitales o Facebook esboza una serie de continuidades y diferencias. Por su misma constitución tecnológica la red virtual se conforma como una red social más transparente en la cual podemos acceder a contactos, "amigos" o Links y a cierta información sobre ellos.

Además esta red permite superar las fronteras espacio-temporales humanas (interacción directa y a distancia) estableciendo nuevos modos de comunicación. En lo que concierne al universo de la prensa, por ejemplo, permite relaciones horizontales, es un tipo de comunicación que no trabaja necesariamente de punto a masa sino que se basa en las au- 
diencias diversificadas. Y por último, permite una reducción considerable en los costos (ya sea de conexión, de insumos y/o personal, etcétera). En la apropiación de las TIC por parte de los periódicos de migrantes se ponen en juego saberes, imaginarios y prácticas de cada colectivo. En primer lugar, las TIC se amoldan a las prácticas y actividades de la comunidad, por ejemplo, sirven para difundir actividades, eventos, cultura, publicidad, etcétera.

En segundo término, los imaginarios que circulan en general en las dos colectividades están presentes en las ediciones digitales (la simbología, las temáticas). El estilo de los periódicos en papel se retoma en las páginas Web y en el Facebook demostrando que hay significaciones que hacen a la identidad referencial de cada colectivo.

En tercer lugar, las versiones on line se siguen posicionando como un enunciador pedagógico cuyo objetivo sigue siendo informar (algo que no se sabe) que es el típico lugar del género periodístico aunque las posibilidades tecnológicas que brindan estas nuevas TIC (por ejemplo, Facebook) permitiría construir una relación más horizontal entre periódico y lector o entre productor y consumidor de información cuyo objetivo podría ser la construcción corporativa de conocimiento y/o información.

Por otro último, el discurso identitario que se construye en las ediciones digitales (más notorio en Renacer) tiene más que ver con una construcción abierta a los vínculos con otros migrantes del mundo (o de la Web). Es en este sentido podemos hablar de una identidad virtual, ya que esta construcción se realiza dentro del ciberespacio, donde las posibilidades (conectividad, instantaneidad, etcétera) y reglas constitutivas son otras. Los rasgos retóricos que se vinculan a la cultura indígena (Wiphala o Tumi), la inclusión de temáticas que difunden las actividades culturales de cada uno de estos grupos, las noticias de sus países de origen y de la diáspora, los editoriales, las temáticas sobre discriminación y xenofobia son referencias identitarias de estos grupos migratorios. La Web permite una mayor circulación de estas referencias y potencia la circulación de estos discursos más allá de la sociedad receptora. Si bien, como señalamos en torno a la construcción corporativa de un discurso, estas nuevas perspectivas parecen no estar explotadas al máximo, empero, podemos arriesgar que así como los periódicos cumplieron y cumplen un rol fundamental en la conformación de transmisión y visibilización de las identidades culturales de una colectividad de migrantes en el seno de la sociedad receptora, la visibilización y la circulación del colectivo en la Web también favorece y contribuye el encuentro (ciber) intra-cultural.

\section{Referencias bibliográficas}

Arfuch, L. (comp.) (2002): Identidades, sujetos y subjetividades. Buenos Aires: Prometeo.

Bauman, Z. (2005): Identidad. Buenos Aires: Losada.

Benítez Larghi, S. (2010). “Tecnologías de información y comunicación (TIC), democracia y sectores populares en Argentina", Revista andamios, Vol. 7, № 14, septiembre-diciembre, pp.11-34. 
Biselli, R. (2006): “La portada de La Nación como dispositivo discursivo", La Trama de la Comunicación, 10. Disponible en: http://rephip.unr.edu.ar/bitstream/handle/2133/447/07.1\%20Ruben\%20Biselli_Ala.pdf?sequence=1 [Consultado $11 / 06 / 2011]$

Busso, M. (2012): “Entre la retirada y el enlazamiento: sobre las identidades on line de la migración”, Revista Question Vol. 1, № 34. Disponible en: http://perio.unlp.edu.ar/ojs/index.php/question/article/view/1440/1299 [Consultado 04/01/2013]

Calello, T. y Aprea, G. (comp.). (2007): Usos de las tics. Una mirada multidimensional. Buenos Aires. Prometeo.

Cardoso de Oliveira, R. (1999): “Los (des) caminos de la identidad”, Apuntes de investigación, 7, pp. 9-29.

Castells, M. (1995): La Era de la Información. Vol. I. La Sociedad Red. Madrid: Alianza Editorial.

Castells, M. (1999): La Era de la Información. Vol. II: Economía, sociedad y cultura. Madrid: Alianza Editorial

Cingolani, G. (2009): “Tapas de semanarios argentinos en el siglo XX: historia discursiva de un dispositivo y dos medios”, Figuraciones. Teoría y crítica de artes, 5. Disponible en: http://www.revistafiguraciones.com.ar/numeroactual/articulo.php?ida=106\&idn=5\&arch=1\#texto (Consultado 11/06/2011)

De Certeau, M. (1996): La invención de lo cotidiano. I. Artes de hacer. México: Universidad Iberoamericana.

De Charras, D. (2003): Sociedad de la información y Nueva Economía: Una revisión Crítica. Disponible en: www.fsoc.uba.ar (Consultado 12/08/2008)

Diminescu, D. (2011): “El migrante conectado. Por un manifiesto epistemológico”, en Hernández, V., Mera, C. Y Oteiza, E. (comp.): Circulación de saberes y movilidades internacionales: Perspectiva latinoamericana. Buenos Aires: Biblos.

Ford, A. (1999): La marca de la bestia. Identificación, desigualdades e infoentretenimiento en la sociedad contemporánea. Buenos Aires: Norma.

Gonzálvez Torralbo, H. (2012): “Comunicación y contacto transnacional: El uso de las nuevas tecnologías de información y comunicación en la constitución de redes migratorias”, en Revilla Blanco, M. y Gómez Johnson, C. (eds.): Caminos de ida y vuelta: redes, migración y desarrollo. Madrid: Catarata.

Hall, S. y du Gay. P. (2003): Cuestiones de identidad cultural. Buenos Aires: Amorrortu.

Hardt, M. y Negri, A. (2002): Imperio. Buenos Aires: Paidós.

Hine, C. (2004): Etnografía virtual. Barcelona: UOC.

Hopenhayn, M. (2001):“Vida insular en la aldea global: paradojas en curso”, Polis, 2. Disponible en: http://polis.revues.org/7857 (Consultado 01/08/2011)

López, G. y Ciuffoli, C. (2012): Facebook es el mensaje. Oralidad, escritura y después. Buenos Aires: Ediciones La Crujía.

Martín Barbero, J. (1991): De los medios a las mediaciones. Comunicación, cultura y hegemonía. Barcelona: Gustavo Gili Editores 
Mejía Estévez, S. (2005). “Transnacionalismo a la ecuatoriana: migración, nostalgia y nuevas tecnologías”, en Herrera, G., Carrillo, M. y Torres, A. (eds.): La migración ecuatoriana, transnacionalismo, redes e identidades. Quito: Flacso.

Mumford, L. (1945): Técnica y civilización. Buenos Aires: Emecé Editores.

Melella, C. (2011): La prensa migrante como recurso de visibilidad y construcción de identidades. El periódico Renacer, de y para la colectividad boliviana en la Argentina. Tesis de posgrado, Universidad de Buenos Aires, Facultad de Ciencias Sociales, Argentina.

Melella, C. (2012): La prensa migrante en la Argentina. Recurso de visibilidad y construcción de identidades: El caso del periódico Renacer, de y para la colectividad boliviana. Saarbrücken: Editorial Académica Española.

Peñaranda Cólera, M.C. (2008): “ ¿Tecnologías que acercan distancias? Sobre los `claroscuros` del estudios de la(s) tecnología(s) en los procesos migratorios transnacionales”, en Santamaría, E. (Ed.): Retos epistemológicos de las migraciones transnacionales. Barcelona: Antrophos.

Peñaranda Cólera, M. C. (2010): “Te escuchas aquí al lado. Usos de las tecnologías de la información y la comunicación en contextos migratorios transnacionales", en Athenea Digital, 19, pp. 239-248. Disponible en: http://psicologiasocial.uab.es/ athenea/index.php/atheneaDigital/article/view/ 787 (Consultado 03/01/2013)

Petris, J. (1998): Crónicas y naciones. Estilos de diarios. Buenos Aires: Cántaro Editores.

Quintar, A. (2007): “Redes sociales y comunidades virtuales”, en Quintar, A; Calello, T y Aprea, G. (comps.): Los usos de las TICs. Una mirada multidimensional. Buenos Aires: Prometeo, pp. 71-85

Sarlo, B. (2004): La imaginación técnica. Sueños modernos de la cultura argentina. Buenos Aires: Nueva Visión.

Steimberg, O. (1993): Semiótica de los medios masivos. Buenos Aires: Atuel.

Steimberg, O. y Traversa, O. (1997): Estilo de época y comunicación mediática. Buenos Aires: Atuel

Tilly, C. (2010): Los movimientos sociales, 1768-2008. Desde sus orígenes a Facebook. Barcelona: Crítica.

Verón, E. (1985): "El análisis del "Contrato de Lectura, un nuevo método para los estudios de posicionamiento de los soportes de los media”, en Les Medias: Experiences, recherchesactuelles, aplications. IREP: París.

Verón, E. (1993): La semiosis social. Fragmentos de una teoría de la discursividad. Barcelona: Gedisa.

Vinelli, N. y C. Rodríguez Esperón (comps.) (2004): Contrainformación. Medios alternativos para la acción política. Buenos Aires: Ediciones Continente.

Virilio, P. (2006): La ciudad sobreexpuesta. Disponible en: http://www.biblioteca.org.ar/libros/131844.pdf (Consultado $09 / 02 / 2013)$

Winocur, R. (2007). “La apropiación de la computadora e Internet en los sectores populares urbanos” Revista Versión, n 19. Winocur, R. (2010): Robinson ya tiene celular. México: Siglo XXI. 